\title{
Impact of Onychomycosis on the Quality of Life: Dermatology Life Quality Index-Based Cross-Sectional Study
}

\author{
Manasa Narayan Kayarkatte Archana Singal Deepika Pandhi \\ Department of Dermatology, Leprosy, and STD, University College of Medical Sciences and GTB Hospital, \\ University of Delhi, Delhi, India
}

\section{Keywords}

Dermatology Life Quality Index · Onychomycosis · Quality of life $\cdot$ Nail fungus $\cdot$ Mycoses

\begin{abstract}
Background: Onychomycosis (OM) is a common fungal infection of the nail unit with a worldwide prevalence of $5 \%$. Though apparently a benign and innocuous entity, it carries significant psychosocial morbidity. The Dermatology Life Quality Index (DLQI) is based on a simple practical questionnaire that considers multiple psychological and social domains. Its utility in OM by far remains unexplored. Objective: To determine the DLQI in patients suffering from OM. Methods: The DLQI questionnaire was answered by 100 patients with an established diagnosis of OM. Results: The mean DLQI of our study subjects was $6.1 \pm 3.3$. Most patients (46\%) belonged to the DLQI 2 group (moderate effect). Among these, most patients reported disease duration of 1-5 years (50\%). Among patients responding to DLQI 3 (very large effect), a higher significant proportion were females (66.7\%). The most inconvenient domain was seeking treatment for $\mathrm{OM}$ and social embarrassment due to the disease. Conclu-
\end{abstract}

(c) 2020 S. Karger AG, Basel

\section{karger@karger.com}

www.karger.com/sad sion: As DLQI is an easy scoring method, it can be used for assessing quality of health in OM. OM causes moderate effect on quality of life (mostly DLQI 2), thereby making its treatment mandatory.

(c) 2020 S. Karger AG, Basel

\section{Introduction}

Onychomycosis $(\mathrm{OM})$ is a fungal infection of the nail unit, affecting nearly $5 \%$ of the general population [1]. Although $\mathrm{OM}$ is the most common onychopathy, its treatment is often neglected by the patients. Treatment of $\mathrm{OM}$ is necessary not only because of unsightly appearance of the nails, but also because it may be a source for dermatophytosis elsewhere in the body and poses as a significant risk factor for cellulitis [2]. Though various methods are available for evaluating quality of life, the Dermatology Life Quality Index (DLQI) is more practical as it is a simple, questionnaire-based index that considers multiple psychological and social domains [3]. It has been used for various dermatological conditions, and it is well known among all dermatologists. Its utility in $\mathrm{OM}$ by far 
Table 1. The domain pertaining to each question in the DLQI

\begin{tabular}{llll}
\hline Question & Domain & $\begin{array}{l}\text { Mean score } \\
\text { in males }\end{array}$ & $\begin{array}{l}\text { Mean score } \\
\text { in females }\end{array}$ \\
\hline Q1 & Pruritus, soreness, stinging & 1.21 & 1.06 \\
Q2 & Social embarrassment & 1.31 & 1.53 \\
Q3 & Interference with shopping/household activities & 0.18 & 0.47 \\
Q4 & Influence on clothing & 0.41 & 0.63 \\
Q5 & Interference with social/leisure activity & 0.34 & 0.84 \\
Q6 & Interference with sports activity & 0.13 & 0.19 \\
Q7 & Interference with working or studying & 0.09 & 0.28 \\
Q8 & Problem with partner/close friend & 0.53 & 0.56 \\
Q9 & Sexual difficulties & 0.03 & 0 \\
Q10 & Difficulty seeking treatment & 1.5 & 1.41 \\
\hline
\end{tabular}

Table 2. DLQI classification $(n=100)$

\begin{tabular}{lcccc}
\hline Group & $\begin{array}{l}\text { Total } \\
\text { score }\end{array}$ & $\begin{array}{l}\text { Males, } \\
n(\%)\end{array}$ & $\begin{array}{l}\text { Females, } \\
n(\%)\end{array}$ & $\begin{array}{l}\text { Patients in our } \\
\text { study, } n(\%)\end{array}$ \\
\hline DLQI 0 (no effect) & 0 & $2(2.9)$ & $2(6.3)$ & $4(4)$ \\
DLQI 1 (small effect) & $1-5$ & $30(44)$ & $13(40.6)$ & $43(43)$ \\
DLQI 2 (moderate effect) & $6-10$ & $34(50)$ & $12(37.5)$ & $46(46)$ \\
DLQI 3 (very large effect) & $11-20$ & $2(2.9)$ & $4(12.5)$ & $6(6)$ \\
DLQI 4 (extremely large effect) & $21-30$ & 0 & $1(3.1)$ & $1(1)$ \\
\hline
\end{tabular}

remains unexplored. A single published study from Thailand showed a mean DLQI of 3.6 in 110 patients with OM [4].

The severity of OM can be assessed with the Onychomycosis Severity Index (OSI) or Scoring Clinical Index for Onychomycosis (SCIO), but it does not consider social or psychological domains. Nail QoL, ONYCHO (Onychomycosis QoL questionnaire), and OnyCOE-t are specific questionnaires for evaluating quality of life in onychopathies. But they have higher complexity compared to DLQI and hence are less commonly used by physicians. There is a lack of a universally accepted scoring system limiting its use to research studies.

\section{Methods}

After institutional ethical committee approval and written informed consent, 100 adult patients with primary OM were recruited in this study. The diagnosis was confirmed by direct microscopic examination with potassium hydroxide or mycological culture or histopathology with hematoxylin and eosin and periodic acid-Schiff. The relevant history was obtained and clinical examination was conducted to identify the morphological variant of $\mathrm{OM}$ and to look for concomitant cutaneous dermatophytosis. All ques- tions of the DLQI questionnaire were asked in the language that the patient understands best, and the responses were scored from 0 to 3 ( 0 being the minimum, 3 being the maximum).

DLQI was calculated based on the response to the standard 10 questions of the domains mentioned as tabulated (Table 1). The patients were further classified based on the total score (Table 2) [3].

\section{Results}

Among the 100 patients with OM, 68 were males and 32 were females, giving a male-to-female ratio of 2.13:1. The mean age of all patients was $40.48 \pm 15.47$ years (range 18-75). Total number of nails involved in individual patients ranged from 1 to 20 (mean $4.6 \pm 4.3$ ). The disease duration ranged from 1 to 360 months (mean: $27.8 \pm 43.8$, SE: 4.3 ). The predominant clinical variant of OM was distal lateral subungual OM (DLSO) in 79, total dystrophic OM (TDO) in 15, and proximal subungual $\mathrm{OM}$ (PSO) and superficial OM (SO) in 3 each. In 41 patients, only fingernails were involved; 40 patients displayed toenail infection only and the rest of the patients $(n=19)$ had involvement of both fingernail and toenails. 
Fig. 1. Percentage of patients with clinical variants of OM in each DLQI group $(n=$ 100). DLSO, distal lateral subungual onychomycosis; PSO, proximal subungual onychomycosis; SO, superficial onychomycosis; TDO, total dystrophic onychomycosis; DLQI, Dermatology Life Quality Index.
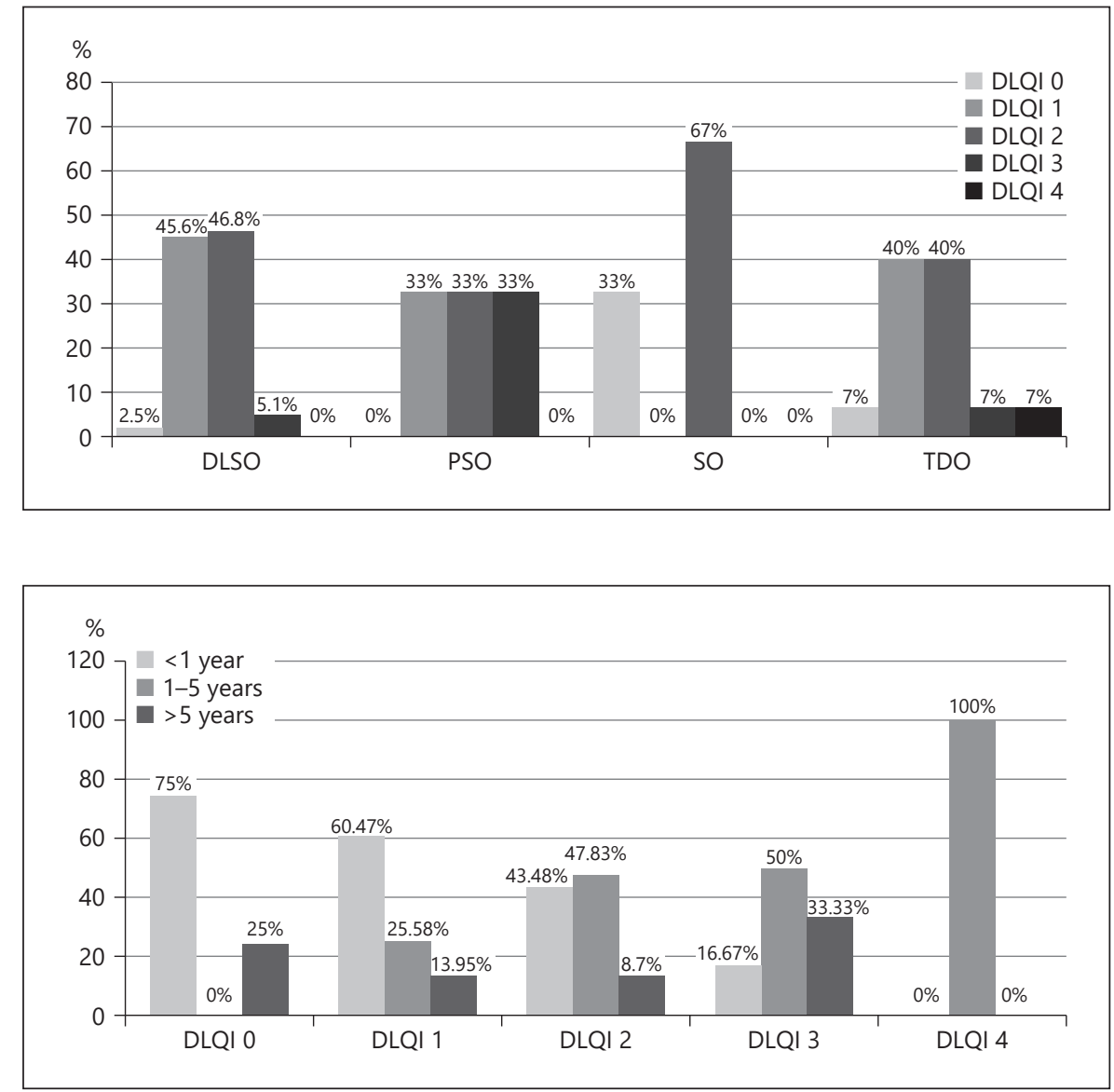

Fig. 2. Percentage of patients with OM with their disease duration and DLQI $(n=100)$. DLQI, Dermatology Life Quality Index.
In patients responding to DLQI 0, (3/4) 75\% had a disease duration $<1$ year. However, $50 \%$ patients responding to DLQI 3, had a much longer disease duration of 1-5 years and only $33.3 \%$ suffered from $>5$ years. However, this association of DLQI scoring and disease duration was not found to be statistically significant (Fig. 2).

Most patients (51.2\%) with fingernail involvement belonged to the DLQI 1 group. Patients with toenail involvement (50\%) and both nail involvement (63.2\%) had a DLQI 2 (Table 3).

As expected, patients with concurrent dermatophytosis belonged more often $(24 / 37,64.9 \%)$ to the DLQI 3 group followed by 11 (29.7\%) patients belonging to DLQI 2 , and $1(2.7 \%)$ to the DLQI 3 and DLQI 4 groups each.

Interestingly, both males and females reported difficulty in seeking treatment for OM despite higher burden of social embarrassment due to the disease. The least reported aspect in the questionnaire was regarding sexual disturbances, secondary to the disease. Only 2 male patients blamed the disease for decreased sexual drive (Table 1). 
Table 3. Nail involvement and DLQI

\begin{tabular}{lcccc}
\hline DLQI & $\begin{array}{l}\text { Fingernail, } \\
n(\%)\end{array}$ & $\begin{array}{l}\text { Toenail, } \\
n(\%)\end{array}$ & $\begin{array}{l}\text { Both, } \\
n(\%)\end{array}$ & $\begin{array}{c}\text { Total, } \\
n(\%)\end{array}$ \\
\hline DLQI 0 & $3(7.3)$ & $1(2.5)$ & 0 & $4(4)$ \\
DLQI 1 (small effect) & $21(51.2)$ & $17(42.5)$ & $5(26.3)$ & $43(43)$ \\
DLQI 2 (moderate effect) & $14(34.1)$ & $20(50)$ & $12(63.2)$ & $46(46)$ \\
DLQI 3 (very large effect) & $3(7.3)$ & $1(2.5)$ & $2(10.5)$ & $6(6)$ \\
DLQI 4 (extremely large effect) & 0 & $1(2.5)$ & 0 & $1(1)$ \\
\hline
\end{tabular}

\section{Discussion}

Quality of life in OM has been studied previously and its impact has been described to be similar to non-melanoma skin cancer and benign growths [5]. The mean DLQI of our study subject was $6.1 \pm 3.3$. In a study by Bunyaratavej et al. [4], the mean DLQI in OM patients was $3.6 \pm 3.75$. A higher mean DLQI could be due to an increase in health consciousness over the past few years since the last study.

The mean DLQI score for females was 6.97 as compared to males who displayed a score of 5.73. A higher percentage of females (12.5\%) belonged to the DLQI 3 group (very large effect) as compared to males (2.9\%). In another study conducted in 2012, women experiencing toenail OM reported worse disease-specific health-related quality of life (HRQoL) [6]. This observation can be explained by the higher cosmetic concerns in females in general. A high proportion of patients with OM (74\%) responded positively to questions on social embarrassment in a study by Drake et al. [7]. A similar observation was made in our study where the mean DLQI of females was 1.5 and that of males was 1.41 with regard to responses on social embarrassment.

Most patients with SO belonged to the DLQI 2 group, and a single patient who belonged to the DLQI 4 group suffered from TDO. A cosmetically more unpleasant appearance in SO and TDO, in comparison to DLSO and PSO, may be a contributing factor for this outcome.

Most of the patients (46.2\%) with a disease duration of $>5$ years belonged to the DLQI 1 group (small effect) as compared to most patients suffering from 1-5 years $(59.5 \%)$ who responded in the DLQI 2 group (moderate effect). One might argue that longer duration of disease should cause higher distress; however, if a disease caused higher distress, the patient would present early, and this would result in shorter duration to presentation. Nevertheless, this association of DLQI scoring and disease duration was not statistically significant.
Patients with concurrent dermatophytosis belonged more often to the DLQI 3 group (very large effect). This may be due to the presence of widespread unsightly and symptomatic lesions of tinea cruris and corporis that are associated with significant pruritus and burning sensation.

While exploring the individual aspects, we noted that the majority of them suffer from social embarrassment due to OM followed by difficulty in seeking treatment for OM. This could be because OM is asymptomatic in the majority and therefore does not get enough priority as far as a visit to a dermatologist is concerned. Question 9 on sexual activities had the lowest score, concordant with the study by Bunyaratavej et al. [4]. It is a well-known fact that OM takes months to years to achieve cure, and elimination of the underlying risk factors for $\mathrm{OM}$ is essential to keep the disease in remission.

\section{Conclusion}

$\mathrm{OM}$ is a common onychopathy, with moderate effect on quality of life, i.e., DLQI 2 (mean DLQI of $6.1 \pm 3.3$ ). As OM can lead to significant distress, especially in women and in those suffering from TDO/SO, the need for an early treatment cannot be undermined.

\section{Statement of Ethics}

Written informed consent was obtained from each patient. The study protocol was approved by the institute's committee on human research.

\section{Disclosure Statement}

The authors have no conflicts of interest to declare. 


\section{Funding Sources}

The authors have no funding sources to declare.

\section{Author Contributions}

All three authors were involved in designing the study, collection of data, analysis, and preparation of the manuscript.

\section{References}

1 Murray SC, Dawber RP. Onychomycosis of toenails: orthopaedic and podiatric considerations. Australas J Dermatol. 2002 May;43(2): $105-12$.

2 Roujeau JC, Sigurgeirsson B, Korting HC, Kerl H, Paul C. Chronic dermatomycoses of the foot as risk factors for acute bacterial cellulitis of the leg: a case-control study. Dermatology. 2004;209(4):301-7.
3 Finlay AY, Khan GK. Dermatology Life Quality Index (DLQI) - a simple practical measure for routine clinical use. Clin Exp Dermatol. 1994 May;19(3):210-6.

4 Bunyaratavej S, Pattanaprichakul P, Leeyaphan C, Chayangsu O, Bunyaratavej S, Kulthanan K. Onychomycosis: A study of self-recognition by patients and quality of life. Indian J Dermatol Venereol Leprol. 2015 May-Jun;81(3):270-4.

5 Warshaw EM, Foster JK, Cham PM, Grill JP, Chen SC. NailQoL: a quality-of-life instrument for onychomycosis. Int $J$ Dermatol. 2007 Dec;46(12):1279-86.
6 Milobratović D, Janković S, Vukičević J, Marinković J, Janković J, Railić Z. Quality of life in patients with toenail onychomycosis. Mycoses. 2013 Sep;56(5):543-51.

7 Drake LA, Scher RK, Smith EB, Faich GA, Smith SL, Hong JJ, et al. Effect of onychomycosis on quality of life. J Am Acad Dermatol. 1998 May;38(5 Pt 1):702-4. 